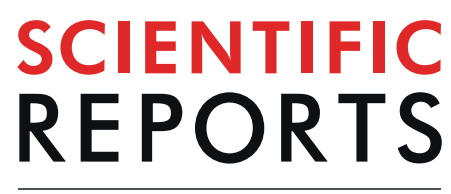

natureresearch

\title{
Expression of Female Sex Hormone Receptors, Connective Tissue Growth Factor and HER2 in Gallbladder Cancer
}

\author{
Beata Hryciuk ${ }^{1,2}$, Rafał Pęksa ${ }^{3}$, Michał Bieńkowski ${ }^{3}$, Bartosz Szymanowski ${ }^{1}$, \\ Barbara Radecka ${ }^{4}$, Kamil Winnik ${ }^{5}$, Jolanta Żok ${ }^{6}$, Natalia Cichowska ${ }^{7}$, Mariola Iliszko ${ }^{8}$ \& \\ Renata Duchnowska ${ }^{1 *}$
}

Gallbladder cancer (GBC) is a highly malignant tumor with poorly understood etiology. An insight into phenotypic features of this malignancy may add to the knowledge of its carcinogenesis and pave the way to new therapeutic approaches. We assessed the expression of female sex hormone receptors (ER $\alpha, E R \beta, P R)$, connective tissue growth factor (CTGF) and HER2 in GBC, and adjacent normal tissue (NT), and determined their prognostic impact. Immunohistochemical (IHC) expression of all biomarkers was performed in formalin-fixed, paraffin-embedded specimens in 60 Caucasian GBC patients (51 women and 9 men). ER $\beta$, cytoPR and CTGF expression were found in $89 \%, 27 \%, 91 \%$ of GBC, and in $63 \%, 87 \%, 100 \%$ of NT, respectively. No ER $\alpha$ expression was found in GBC and NT. Strong (3+) HER2 expression by IHC or HER2 amplification was seen in five GBC (10.4\%). A positive correlation was found between HER2 and CTGF and ER $\beta$ expression in GBC and matched NT. In the multivariate analysis, patient age $>70$ years, tumor size and ER $\beta$ expression in GBC was highly predictive for $O S(p=0.003)$. The correlation between HER2, CTGF and ER $\beta$ expression in GBC and NT may indicate the interaction of these pathways in physiological processes and gallbladder pathology.

Gallbladder cancer (GBC) is an aggressive malignant tumor originating from epithelial cells of the mucous membrane. The etiology of GBC is poorly understood, and its global prevalence is characterized by considerable regional variations ${ }^{1-4}$. The highest incidence is reported in Chile, India, Pakistan, Bolivia, Central Europe, Israel, and in Native Americans and Americans of Mexican origin ${ }^{1-4}$. The risk of developing GBC is higher in patients with chronic inflammatory processes caused by gallstones with resulting calcification of the gallbladder wall ("porcelain gallbladder"), and with infections such as Salmonella typhi or Salmonella paratyphi ${ }^{3-5}$. GBC is about two to six times more common in women compared to men, and its incidence steadily increases with age ${ }^{1-5}$.

Estrogens are key signaling molecules that regulate various physiological processes and play a major role in many pathological conditions, such as hormone-dependent cancers. Expression of female sex hormone receptors in GBC has been analyzed in a few studies including mainly Asian populations, and provided inconsistent results $^{6-14}$. Several small studies demonstrated overexpression of human epidermal growth factor receptor type 2 (HER2) and HER gene amplifications or mutations ${ }^{15-27}$. Connective Tissue Growth Factor (CTGF) was found to be expressed in various stages of the GBC carcinogenesis ${ }^{28}$. GBC carries a poor prognosis and most patients succumb to their disease. An insight into phenotypic features of this tumor may add to the knowledge of its carcinogenesis and pave the way to new therapeutic approaches. In the present study we investigated the expression of female sex hormone receptors: estrogen receptor alpha $(E R \alpha)$, ER beta $(E R \beta)$ and progesterone (PR), as well as CTGF and HER2 in a relatively large group of Caucasian GBC patients. Additionally, we assessed prognostic value of these biomarkers.

${ }^{1}$ Department of Oncology, Military Institute of Medicine, Warsaw, Poland. ${ }^{2}$ Mazovian Center for Lung Diseases and Tuberculosis, Division III in Otwock, Otwock, Poland. ${ }^{3}$ Pathology Department, Medical University of Gdańsk, Gdańsk, Poland. ${ }^{4}$ University of Opole, Institute of Medical Science, Opole, Poland. ${ }^{5}$ Pathology Department Provincial Specialist Hospital, Słupsk, Poland. ' Department of Chemotherapy, Center of Pulmonology and Chemotherapy, Szklarska Poręba, Poland. ${ }^{7}$ Department of Oncology and Radiotherapy, Medical University of Gdańsk, Gdańsk, Poland. ${ }^{8}$ Department of Biology and Medical Genetics, Medical University of Gdańsk, Gdańsk, Poland. *email: rdtt@wp.pl 


\section{Results}

Patient characteristics. The study group included 60 GBC Caucasian patients (51 women and 9 men). The average age of patients was 67 years (range, 31-97 years), median BMI was 26.2 (range, 17.7-4.3) and in 35 patients (58\%) GBC coexisted with gallstones. The simple cholecystectomy or en bloc resection of gallbladder with segments IVb and V of the liver, with or without regional lymph node dissection was performed in 49 patients (82\%). After a median follow-up of 8 months (range $0-167)$, 31 patients (52\%) developed relapse, 29 of whom $(48 \%)$ received palliative chemotherapy. All cases were diagnosed as adenocarcinoma, not otherwise specified. Pathologic stages T1, T2, T3 and T4 were found in $13(22 \%), 23(38 \%), 14(23 \%)$ and $4(6.7 \%)$ of patients, respectively, and in 6 patients (10\%) pT status was not determined. Pathologic N0 and pN1 stages were seen in 11 $(18 \%)$ and $13(22 \%)$ of patients, respectively, and in 36 patients $(60 \%) \mathrm{pN}$ status was not determined. High (G3), intermediate (G2), and low-grade (G1) adenocarcinoma was diagnosed in 11 (18\%), $29(48 \%)$, and 11 (18\%) of cases, respectively, and in nine patients (15\%) grade was not determined (Table 1).

Biomarker expression. ER $\beta$, cytoPR and CTGF expression was found in 40 (89\%), 15 (27\%) and 48 (91\%) cases of GBC and in $22(63 \%), 34$ (87\%) and $38(100 \%)$ of NT, respectively (Table 2). No ER $\alpha$ or nuclear PR expression was found in GBC and in adjacent NT. Loss of tissue spots for ER $\beta$, cytoPR, HER2 and CTGF analysis was $15(25 \%), 5(8.3 \%), 12(20 \%), 7(11.7 \%)$ in GBC and $25(41.7 \%), 21(35 \%), 21(35 \%), 22(36.7 \%)$ in adjacent NT, respectively. Compared to NT, GBC specimens showed higher expression of $\operatorname{ER} \beta(\mathrm{p}<0.01)$, and lower expression of HER2 (H-score) and cytoPR ( $\mathrm{p}<0.01$ and $\mathrm{p}<0.01$, respectively). IHC HER2 $2+$ expression was found in $6(13 \%)$ and $6(15 \%)$ of GBC and NT, respectively. IHC HER2 3+ or $2+$ expression and HER2 amplification was seen in five GBC (10.4\%; Fig. 1C,D,F). Intermediate HER2 expression (HER2 2+) was also found in six normal NT, none of which with HER2 gene amplification by FISH (Table 2). There was no significant difference in the expression of CTGF between GBC and NT $(p=0.16)$. A positive correlation was found between HER2 and CTGF expression in GBC and matched NT ( $p=0.003$ and $p<0.001$, respectively). ER $\beta$ and HER2 expression in GBC and in matched NT showed a borderline correlation $(p=0.056 \mathrm{p}=0.052$, respectively). Expression of cytoPR in NT was higher in patients with gallstones $(\mathrm{p}=0.04)$. There was no association between ER $\beta$, cytoPR, HER2 and CTGF expression in GBC and the presence of gallstones ( $p=0.39 ; p=1.0 ; p=1.0 ; p=0.17 ; p=1.0$, respectively).

Clinical outcomes. Median overall survival was 13.6 months (range, 1-167). In the univariate analysis, age above 70 years $(\mathrm{HR}=1.88 ; 95 \% \mathrm{CI} 1.07-3.29 ; \mathrm{p}=0.03)$ and $\mathrm{pT}$ stage $(\mathrm{HR}=1.43 ; 95 \% \mathrm{CI} 1.03-1.99 ; \mathrm{p}=0.03)$ were correlated with shorter OS (Fig. 2A,B). Expression of ER $\beta$ in GBC was correlated with shorter $(p=0.02)$, and in NT with longer OS $(p=0.03)$ (Fig. $2 C, D)$. HER2 expression in GBC did not impact OS $(p=0.12)$. In the multivariate analysis, shorter OS was correlated with age above 70 years, higher $\mathrm{pT}$ stage, and expression of ER $\beta$ in $\mathrm{GBC}(\mathrm{p}=0.003)$.

\section{Discussion}

We have performed a comprehensive analysis of female sex hormone receptors, HER2 and CTGF in GBC and in adjacent NT in a relatively large group of Caucasian patients. The lack of ER $\alpha$ expression in GBC and in adjacent NT confirms the results of studies published after $2007^{12-14}$. ER expression demonstrated in some earlier reports was likely due to nonspecific staining with antibodies involving both ER $\alpha$ and ER $\beta$ receptors ${ }^{6-11}$. In these studies ER expression was demonstrated in both metaplasia, and GBC, irrespective of its differentiation ${ }^{6,7,9}$. The prognostic value of ER expression in GBC is contradictory. Two studies from India suggested that the expression of ER and PR in GBC does not have an impact on the prognosis ${ }^{12,13}$. In our study ER $\beta$ expression in GBC was correlated with a shorter OS, and in NT with a longer OS. This finding is intriguing but may be incidental owing to multiple comparisons. In some malignancies, including breast, ovarian and prostate cancers, ER $\beta$ plays a suppressive and anti-proliferative roles ${ }^{29,30}$. In contrast to ER $\beta$, expression of cytoPR was higher in NT compared to GBC, and was associated with the co-existence of gallstones. Additionally, cytoPR expression was negatively correlated with CTGF expression. A few studies demonstrated PR expression (including cytoPR) in GBC $\mathrm{C}^{6,11,12}$. In the Baskaran et al. study ${ }^{11} \mathrm{PR}$ was more often expressed in neoplastic compared to benign lesions, and in the Nakamura et al. study ${ }^{6}$, PR expression was lower in the metaplasia and high-grade GBC. Some studies did not demonstrate PR expression in GBC, which may be related to the use of antibodies detecting only nuclear PR expression (PR-A isoform), whereas isoform $\mathrm{B}$ (PR-B) is also expresses in the cell cytoplasm ${ }^{13,14,31}$. The different functions of three PR isoforms (A, B, and C) are well recognized in breast cancer ${ }^{32-34}$. PR-B activates expression of progesterone-dependent genes by palindromic-progesterone-response DNA elements related to the metabolism of sex hormones ${ }^{32-34}$.

High expression of ER $\beta$ GBC found in this study supports a possible role of anti-estrogen therapy in GBC, probably with a different approach than in breast cancer though. In obese postmenopausal women, adipose tissue is the main source of estrogen biosynthesis, and this hormone has been shown to increase cholesterol level in bile and decrease gallbladder contractility ${ }^{35}$. Likewise, physiological processes in premenopausal women, such as menstrual cycle phase and pregnancy, or contraceptive use, are accompanied by changes of gallbladder functions and increased gallstone formation ${ }^{36,37}$. A recent study postulated that cholesterol gallstones in women are related to differences in liver cholesterol metabolism in response to estrogen, a process mediated by up-regulating of the ESR1 (ER $\alpha$ coding gene) expression ${ }^{38}$. In other study ESR1 polymorphic variants: IVS1-397C > T, ESR1 IVS1$351 \mathrm{~A}>\mathrm{G}$ and ESR2-789 A > C correlated with GBC risk, mediated through gallstone dependent pathway ${ }^{39}$.

Tamoxifen is the oldest and most-prescribed selective estrogen receptor modulator in breast cancer patients. A Turkish study demonstrated increased risk of gallstone formation in postmenopausal breast cancer patients administered tamoxifen ${ }^{40}$, but this effect was not confirmed in another study performed in India ${ }^{41}$. Interestingly, 


\begin{tabular}{|c|c|}
\hline Variable & n (\%) \\
\hline Age at GBC diagnosis (years) & $60(100)$ \\
\hline Mean & 67 \\
\hline Range & $61-76.5$ \\
\hline Sex & $60(100)$ \\
\hline Women & $51(85)$ \\
\hline Men & $9(15)$ \\
\hline Body mass index $\left(\mathrm{kg} / \mathrm{m}^{2}\right)$ & $34(57 \%)$ \\
\hline Mean & 26.2 \\
\hline Range & $17.7-45.3$ \\
\hline Gallstones & $60(100)$ \\
\hline No & $17(28.3)$ \\
\hline Yes & $35(58.3)$ \\
\hline Unknown & $8(13.4)$ \\
\hline Histology & $60(100)$ \\
\hline Adenocarcinoma, NOS & $60(100)$ \\
\hline Grade (G) & $60(100)$ \\
\hline G1 & $11(18.3)$ \\
\hline $\mathrm{G} 2$ & $29(48.3)$ \\
\hline G3 & $11(18.3)$ \\
\hline G4 & 0 \\
\hline Unknown & $9(15.1)$ \\
\hline pT stage & $60(100)$ \\
\hline 1 & $13(21.7)$ \\
\hline 2 & $23(38.3)$ \\
\hline 3 & $14(23.3)$ \\
\hline 4 & $4(6.7)$ \\
\hline Unknown & $6(10.0)$ \\
\hline pN stage & $60(100)$ \\
\hline 0 & $11(18.3)$ \\
\hline 1 & $13(21.7)$ \\
\hline Unknown & $36(60.0)$ \\
\hline Surgery & $60(100)$ \\
\hline Resection $^{\mathrm{a}}$ & $49(82.0)$ \\
\hline Diagnostic laparoscopy & $6(10.0)$ \\
\hline Unknown & $5(8.0)$ \\
\hline Disease recurrence & $60(100)$ \\
\hline No & $29(48.3)$ \\
\hline Yes & $31(51.7)$ \\
\hline Palliative chemotherapy & $60(100)$ \\
\hline No & $14(23.3)$ \\
\hline Yes & $29(48.3)$ \\
\hline Unknown & $17(28.4)$ \\
\hline
\end{tabular}

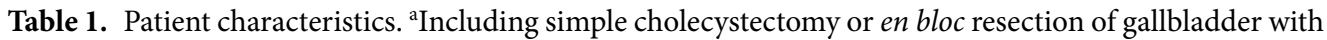
segments IVb and $\mathrm{V}$ of the liver with or without regional lymph nodes.

\begin{tabular}{|l|l|l|l|l|}
\hline \multirow{2}{*}{ Biomarker } & \multicolumn{3}{|l|}{ GBC (N, \%) } & NT (N, \%) \\
\cline { 2 - 5 } & Positive & Negative & Positive & Negative \\
\hline ER 3 & $40(89 \%)$ & $5(11 \%)$ & $22(63 \%)$ & $13(37 \%)$ \\
\hline cytoPR & $15(27 \%)$ & $40(73 \%)$ & $34(87 \%)$ & $5(13 \%)$ \\
\hline HER2 (2+) IHC & $6(13 \%)$ & $42(87 \%)$ & $6(15 \%)$ & $33(85 \%)$ \\
\hline $\begin{array}{l}\text { HER2 (3+) IHC or FISH } \\
\text { positive }\end{array}$ & $5(10.4 \%)$ & $43(89.6 \%)$ & $0(0 \%)$ & $39(100 \%)$ \\
\hline CTGF & $48(91 \%)$ & $5(9 \%)$ & $38(100 \%)$ & $0(0 \%)$ \\
\hline
\end{tabular}

Table 2. Biomarkers expression in the GBC and in adjacent normal tissue (GBC: gallbladder cancer, NT: adjacent normal tissue). 


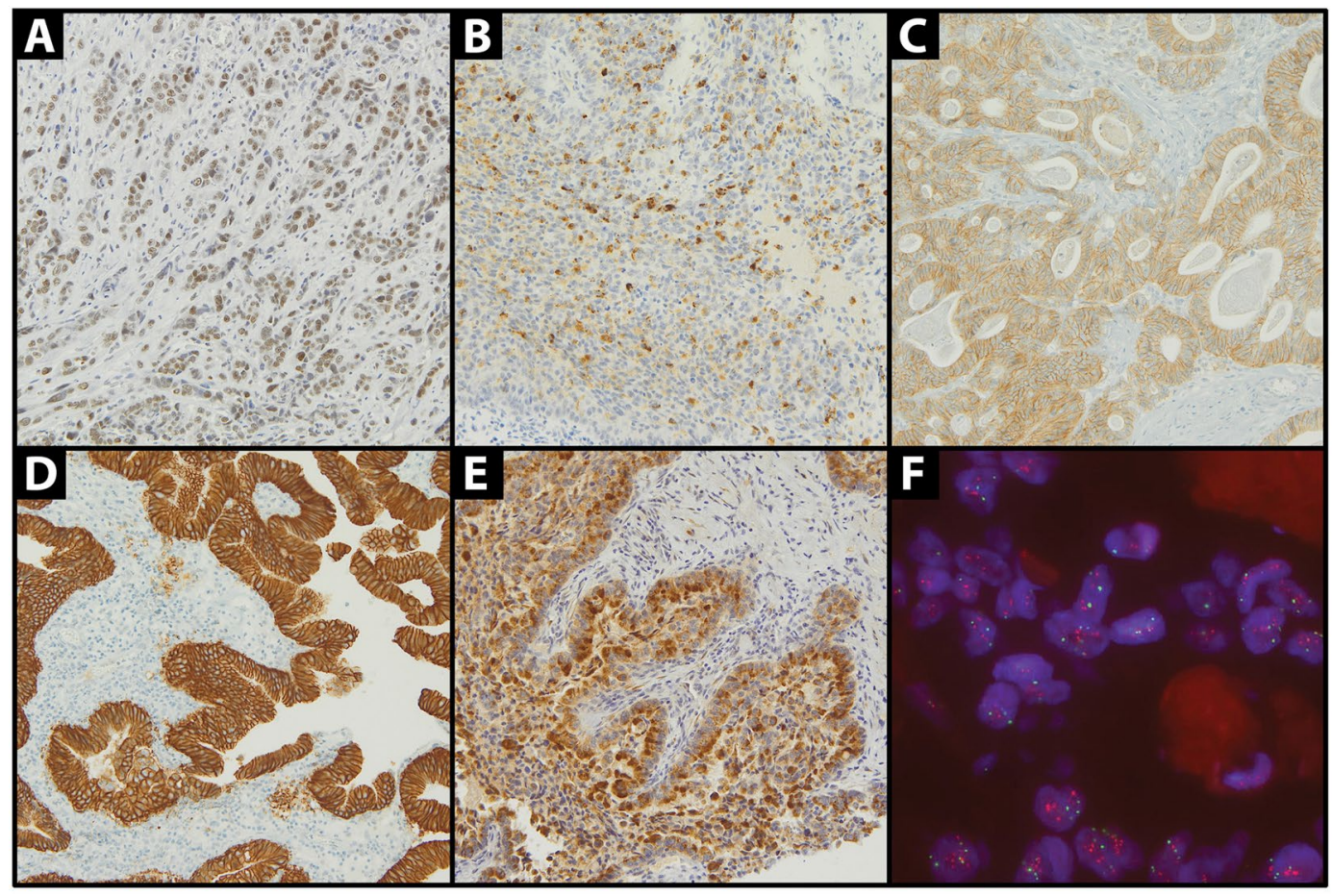

Figure 1. Immunohistochemical expression (magnification X20): (A) ER $\beta$; (B) cytoPR; (C) HER2 (2+); (D) HER2 (3+); (E) CTGF. and (F) FISH HER2 gene amplification.
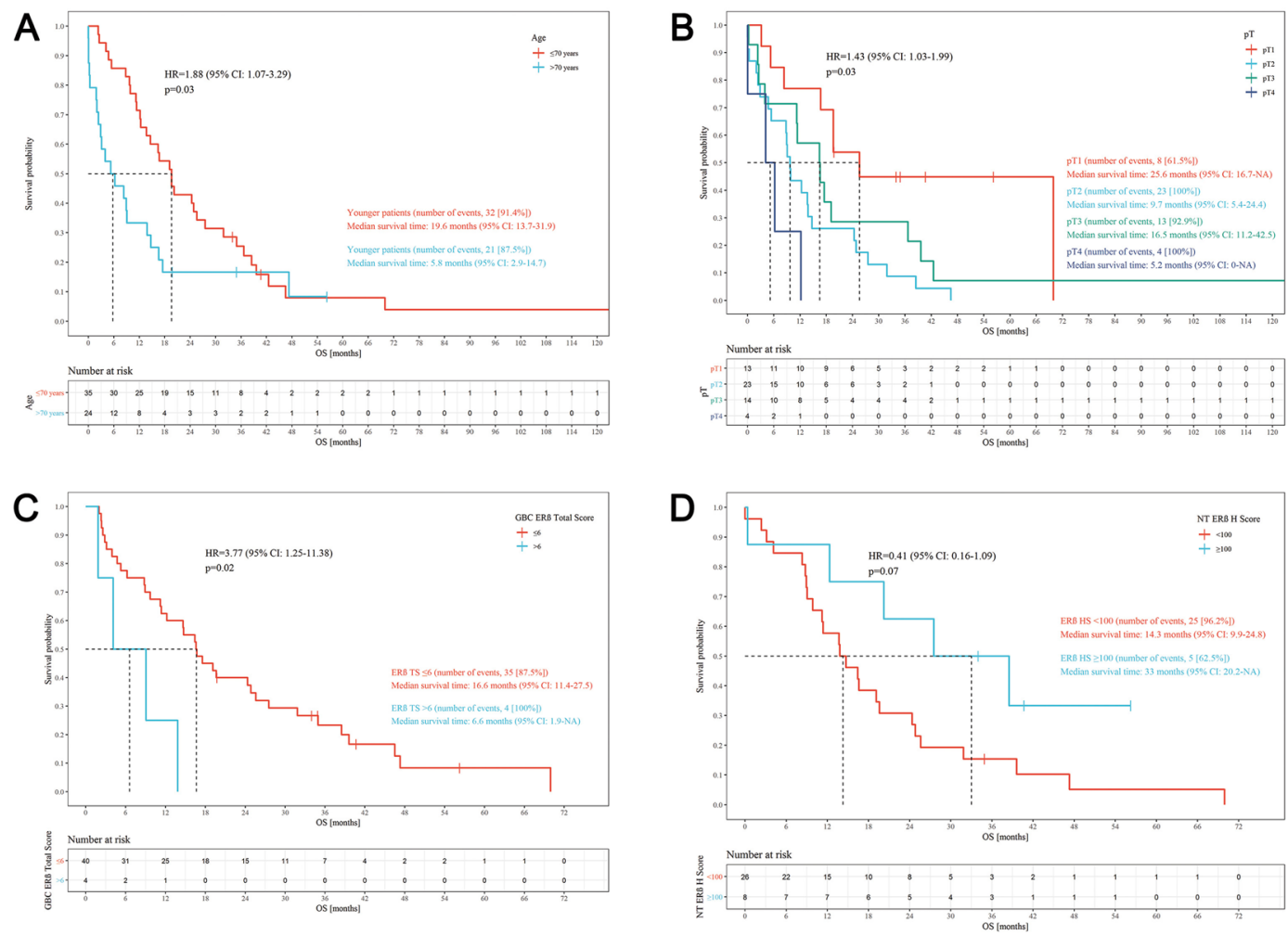

Figure 2. Kaplan-Meier overall survival curves. (A) Age $\leq 70$ vs $>70$ years; (B) pT stage; (C) ER $\beta$ expression in $\mathrm{GBC} \leq 6$ vs $>6$; (D) ER $\beta$ expression in normal adjacent tissue $H$-score $<100$ vs $\geq 100$. 


\begin{tabular}{|l|l|l|l|l|l|l|}
\hline Target & Manufacturer & Dilution & Epitope retrival & Incubation & $\begin{array}{l}\text { Control } \\
\text { tissue }\end{array}$ & $\begin{array}{l}\text { Method of } \\
\text { evaluation }\end{array}$ \\
\hline ER $\alpha$ & $\begin{array}{l}\text { DAKO; anti-human; rabbit } \\
\text { clone EP1 }\end{array}$ & RU & HIER & $20^{\prime}$ & BC & SQ \\
\hline ER 3 & $\begin{array}{l}\text { Abcam; anti-human; rabbit } \\
\text { clone EPR3778; ab133467 }\end{array}$ & $1: 70$ & HIER & night incubation & BC & SQ \\
\hline PgR & $\begin{array}{l}\text { DAKO; anti-human; } \\
\text { mouse clone 636 }\end{array}$ & RU & HIER & $\begin{array}{l}20^{\prime}+\text { linker mouse } \\
15^{\prime}\end{array}$ & BC & SQ \\
\hline HER2 & Ventana; rabbit clone 4B5 & RU & $\begin{array}{l}\text { Epitope retrival } \\
\text { in machine }\end{array}$ & $20^{\prime}$ & BC & SQ \\
\hline CTGF & $\begin{array}{l}\text { Santa Cruz, California; } \\
\text { goat sc-14939 }\end{array}$ & $1: 100$ & HIER & $60^{\prime}$ & SM & SQ \\
\hline
\end{tabular}

Table 3. Antibodies, dilutions and methods of evaluation. RU: ready to use; HIER: Heat-Induced Epitope Retrieval; SQ: semiquantitative; BR: breast cancer; SM: smooth muscle.

patients with ESR1-mutated breast cancer showed better response to fulvestrant, a hormonal protein degrader, compared to aromatase inhibitors ${ }^{42}$. Further research is warranted to assess the fulvestrant activity in GBC.

The present study did not show different CTGF expression in GBC and adjacent NT, or the prognostic value of this biomarker. The role of CTGF in GBC progression and its favorable prognostic impact was earlier reported in a Chilean study ${ }^{28}$. This effect may be attributed to the stromal response to the neoplastic process in an autocrine or paracrine manner ${ }^{28}$. Inconsistent results of both studies may be due to different etiology of GBC in the Latin American and Caucasian populations ${ }^{3,4,6}$.

HER2 overexpression or gene amplification occur in $12-15 \%$ of $\mathrm{GBC}^{15,20,22-25}$. In our study, using the breast cancer criteria, IHC $2+$ or $3+$ expression was found in $15 \%$ of cases, more than a half of which (8.3\%) showed a true HER 2 positivity (IHC $3+$ expression or FISH amplification). Aberrant HER family signaling may be important in the development and progression of $\mathrm{GBC}^{15,20}$. Some studies reported adverse prognostic impact of HER2 expression ${ }^{16,23-26,43}$, but others, including ours, did not show such correlation ${ }^{27,44}$. A few studies have investigated anti-HER2 therapy in advanced GBC ${ }^{45-49}$. This approach was also attempted in bilary tract cancer (BTC) patients. Two phase II studies in unselected BTC patients did not show lapatinib activity ${ }^{45,46}$. In the MyPathway trial including seven HER2-positive BTC patients treated with the combination of the anti-HER2 antibodies, trastuzumab and pertuzumab, the objective response rate was $29 \%{ }^{47}$. In the NCT02675829 clinical trial, the response rate for ado-trastuzumab emtansine in HER2 amplified BTC patients was $17 \%{ }^{48}$. Recently, a basket trial showed the activity of a pan-HER tyrosine kinase inhibitor neratinib in HER2-mutant BTC patients ${ }^{49}$. In our study expression of HER2 and CTGF in GBC was positively correlated with their expression in surrounding NT. This finding may suggest a connection between these pathways in both physiological and pathological processes of the gallbladder. For example, in breast cancer, there is a progestin-independent relationship between the pathways for steroid receptors and growth factor receptors ${ }^{50}$.

Similarly to other GBC studies, age over 70 years and higher $\mathrm{pT}$ stage adversely impacted $\mathrm{OS}^{1-5}$.

Our study contributes to the current knowledge on the biology of GBC, but owing to its retrospective nature and the relatively small group of patients, should be interpreted cautiously. In recent years, somatic profiling with next-generation sequencing has identified several genes, including TP53, SMAD4 and KRAS, which seem to play a role in GBC carcinogenesis ${ }^{51-53}$. At present, a number of agents targeting new pathways are being investigated in clinical trials in GBC patients. Our tissue material and clinical database may be exploited in future scientific projects.

\section{Materials and Methods}

Study population. This study was approved by the Institutional Review Board of the coordinating center, the Military Institute of Medicine in Warsaw, Poland. The patients were diagnosed and underwent surgery between 2004 and 2016 in four oncology centers in Poland. Demographic, clinicopathologic, and clinical follow-up data were extracted from medical records. All data were coded to secure full protection of personal information, therefore, patient consent was not sought. All research was performed in accordance with relevant guidelines and regulations.

Immunohistochemical analysis. The starting material from each patient was an archival formalin-fixed, paraffin-embedded (FFPE) surgical specimen of the primary GBC. The pathologic diagnosis was confirmed by a board-certified pathologist (RP) who reviewed FFPE tissue sections stained with hematoxylin and eosin. A representative paraffin block from each specimen was chosen for immunohistochemical analysis (IHC). The two biopsy specimens of GBC and surrounding NT ("tissue core") were placed on the previously prepared tissue-free paraffin blocks ("recipients"). Tissue microarrays were constructed using Manual Tissue Arrayer I by Beecher Instruments (MTAI, K7 BioSystems). IHC was performed on $4 \mu \mathrm{m}$ thick tissue microarray sections. The staining was conducted according to the manufacturers' protocols (Table 3). ER $\alpha, E R \beta$ and PR were evaluated in the cell nuclei or/and cytoplasm. The occurrence of nuclear and/or cytoplasmatic $\mathrm{ER} \alpha, \mathrm{ER} \beta, \mathrm{PR}$ reaction in at least $1 \%$ cells was considered a positive reaction. CTGF expression was evaluated in the cytoplasm and cell membrane, and HER2 expression in the cell membrane. For all biomarkers the intensity of staining was defined as weak (1), moderate (2), or strong (3). The H-score was calculated for each biomarker by the formula: $3 \times \%$ strong cellular staining (cytoplasmic, nuclear and/or membranous) $+2 \times \%$ moderate staining $+1 \times \%$ weak staining. This made a range of $0-300$. Additionally, ER $\alpha, E R \beta$ and PR were scored by the Allred method. This system is graded on a scale of 0 to 8 , with 0 indicating a completely negative result and 2 to 8 used as a means of semiquantifying the immunoreactivity ${ }^{54}$. Based on breast cancer criteria for HER2-positivity only samples showing strong 
expression (scored $3 \mathrm{IHC}$ ), defined as uniform and intense membrane staining of at least $10 \%$ of invasive tumor cells, were considered positive. The samples showing intermediate expression (scored 2 IHC) were subjected to additional analysis of HER2 gene copy number using fluorescence in situ hybridization (FISH). Gene amplification by FISH was defined as a FISH ratio (HER2/centromeric probe for chromosome 17 ratio) of greater than 2.0. FISH-positive patients were considered HER2-positive ${ }^{55}$. Figure 1 shows examples of positive control staining for ER $\beta$, cytoPR, HER2 (2+), HER2 (3+), CTGF and HER2 gene amplification.

Statistical analysis. The statistical analysis was conducted using statistical environment R, rev. 3.4.3., on the basis of data contained in a study-dedicated database. This analysis included all available clinical and pathological variables. Expression of individual biomarkers was compared using the intraclass correlation coefficient (ICC), assuming kappa $<0.4$ as weak, $\geq 0.4$ as sufficient, $\geq 0.6$ as good and $\geq 0.75$ as optimal correlation, and with Kendall tau test - ICC package. The Mann-Whitney-Wilcoxon test was used to compare biomarker expression between GBC and surrounding NT. Overall survival (OS) was computed using the Kaplan-Meier method, starting from GBC diagnosis to the date of death or the last follow up. Univariate and multivariate analyses were performed using the log-rank test, Wilcoxon test, and Cox proportional hazard and logistic regression.

Received: 18 October 2019; Accepted: 27 December 2019;

Published online: 05 February 2020

\section{References}

1. Siegel, R. L., Miller, K. D. \& Jemal, A. Cancer statistics, 2018. CA Cancer J. Clin. 68, 7-30 (2018).

2. Randi, G., Franceschi, S. \& La Vecchia, C. Gallbladder cancer worldwide: geographical distribution and risk factors. Int. J. Cancer. 118, 1591-1602 (2006).

3. Goetze, T. O. Gallbladder carcinoma: Prognostic factors and therapeutic options. World J. Gastroenterol. 21, 12211-12217 (2015).

4. Hundal, R. \& Shaffer, E. A. Gallbladder cancer: epidemiology and outcome. Clin. Epidemiol. 6, 99-109 (2014).

5. Espinoza, J. A. et al. The inflammatory inception of gallbladder cancer. Biochim. Biophys. Acta. 1865, 245-254 (2016).

6. Nakamura, S., Muro, H. \& Suzuki, S. Estrogen and progesterone receptors in gallbladder cancer. Jpn. J. Surg. 19, 189-194 (1989).

7. Yamamoto, M., Nakajo, S. \& Tahara, E. Immunohistochemical analysis of estrogen receptors in human gallbladder. Acta Pathol. Jpn. 40, 14-21 (1990)

8. Ko, C. Y., Schmit, P., Cheng, L. \& Thompson, J. E. Estrogen receptors in gallbladder cancer: detection by an improved immunohistochemical assay. Am. Surg. 61, 930-933 (1995).

9. Malik, I. A. et al. Immuno-histochemical analysis of estrogen receptors on the malignant gallbladder tissue. J. Pak. Med. Assoc. 48, 123-126 (1998)

10. Sumi, K., Matsuyama, S., Kitajima, Y. \& Miyazaki, K. Loss of estrogen receptor beta expression at cancer front correlates with tumor progression and poor prognosis of gallbladder cancer. Oncol. Rep. 12, 979-984 (2004).

11. Baskaran, V., Vij, U., Sahni, P., Tandon, R. K. \& Nundy, S. Do the progesterone receptors have a role to play in gallbladder cancer? Int. J. Gastrointest. Cancer. 35, 61-68 (2005).

12. Shukla, P. J. et al. Is there a role for estrogen and progesterone receptors in gall bladder cancer? HPB . 9, 285-288 (2007).

13. Park, J. S. et al. Estrogen receptor alpha, estrogen receptor beta, and progesterone receptor as possible prognostic factor in radically resected gallbladder carcinoma. J. Surg. Res. 152, 104-110 (2009).

14. Albores-Saavedra, J., Henson, D. E., Moran-Portela, D. \& Lino-Silva, S. Cribriform carcinoma of the gallbladder: a clinicopathologic study of 7 cases. Am. J. Surg. Pathol. 32, 1694-1698 (2008).

15. Roa, I. et al. Overexpression of the HER2/neu gene: a new therapeutic possibility for patients with advanced gallbladder cancer. Gastrointest. Cancer Res. 7, 42-48 (2014).

16. Singh, A. et al. Prognostic significance of HER-2 and p53 expression in gallbladder carcinoma in North Indian patients. Oncology. 91, 354-360 (2016)

17. Matsuyama, S. et al. Gallbladder cancers rarely overexpress HER-2/neu, demonstrated by Hercep test. Oncol. Rep. 11, 815-819 (2004).

18. Kim, Y. W. et al. Expression of the c-erb-B2 and p53 protein in gallbladder carcinomas. Oncol. Rep. 8, 1127-1132 (2001).

19. Harder, J. et al. EGFR and HER2 expression in advanced biliary tract cancer. World J. Gastroenterol. 2009 15, 4511-4517 (2009).

20. Kawamoto, T. et al. Overexpression and gene amplification of EGFR, HER2, and HER3 in biliary tract carcinomas, and the possibility for therapy with the HER2-targeting antibody pertuzumab. J. Gastroenterol. 50, 467-479 (2015).

21. Li, M. et al. Whole-exome and targeted gene sequencing of gallbladder carcinoma identifies recurrent mutations in the ErbB pathway. Nat. Genet. 46, 872-876 (2014).

22. Yan, M. et al. HER2 expression status in diverse cancers: review of results from 37,992 patients. Cancer Metastasis Rev. 34, 157-164 (2015).

23. Pujani, M. et al. Expression of human epidermal growth factor receptor (Her 2/neu) and proliferative marker Ki-67: association with clinicopathological parameters in gallbladder carcinoma. Asian Pac. J. Cancer Prev. 17, 3903-3909 (2016).

24. Shafizadeh, N., Grenert, J. P., Sahai, V. \& Kakar, S. Epidermal growth factor receptor and HER-2/neu status by immunohistochemistry and fluorescence in situ hybridization in adenocarcinomas of the biliary tree and gallbladder. Hum. Pathol. 41, 485-492 (2010).

25. Ooi, A. et al. Gene amplification of Myc and its coamplification with ERBB2 and EGFR in gallbladder adenocarcinoma. Anticancer. Res. 29, 19-26 (2009).

26. Chaube, A., Tewari, M., Garbyal, R. S., Singh, U. \& Shukla, H. S. Preliminary study of p53 and c-erbB-2 expression in gallbladder cancer in Indian patients manuscript. BMC Cancer. 6, 126 (2006).

27. Suzuki, T., Takano, Y., Kakita, A. \& Okudaira, M. An immunohistochemical and molecular biological study of c-erbB-2 amplification and prognostic relevance in gallbladder cancer. Pathol. Res. Pract. 189, 283-292 (1993).

28. Garcia, P. et al. Connective tissue growth factor immunohistochemical expression is associated with gallbladder cancer progression. Arch. Pathol. Lab. Med. 137, 245-250 (2013).

29. Lazennec, G. Estrogen receptor beta, a possible tumor suppressor involved in ovarian carcinogenesis. Cancer Lett. 231, 151-157 (2006).

30. Omoto, Y. \& Iwase, H. Clinical significance of estrogen receptor $\beta$ in breast and prostate cancer from biological aspects. Cancer Sci. 106, 337-343 (2015).

31. Leslie, K. K. et al. Progesterone receptor isoform identification and subcellular localization in endometrial cancer. Gynecol. Oncol. 96, 32-41 (2005).

32. Richer, J. K. et al. Differential gene regulation by the two progesterone receptor isoforms in human breast cancer cells. J. Biol. Chem. 277, 5209-5218 (2002).

33. Piasecka, D., Składanowski, A. C., Kordek, R., Romańska, H. M. \& Sądej, R. Aspects of progesterone receptor (PR) activity regulation - impact on breast cancer progression. Postepy Biochem. 61, 198-206 (2015).

34. Scarpin, K. M., Graham, J. D., Mote, P. A. \& Clarke, C. L. Progesterone action in human tissues: regulation by progesterone receptor (PR) isoform expression, nuclear positioning and coregulator expression. Nucl. Recept. Signal. 7, e009 (2009). 
35. Cleary, M. P. \& Grossmann, M. E. Obesity and breast cancer: the estrogen connection. Endocrinology. 150, 2537-2542 (2009).

36. Everson, G. T., McKinley, C., Lawson, M., Johnson, M. \& Kern, F. Jr. Gallbladder function in the human female: effect of the ovulatory cycle, pregnancy, and contraceptive steroids. Gastroenterology. 82, 711-719 (1982).

37. Pandey, M. \& Shukla, V. K. Lifestyle, parity, menstrual and reproductive factors and risk of gallbladder cancer. Eur. J. Cancer Prev. $12,269-272(2003)$.

38. Wang, H. H., Portincasa, P. \& Wang, D. Q.-H. Molecular pathophysiology and physical chemistry of cholesterol gallstones. Front. Biosci. 13, 401-423 (2008).

39. Srivastava, A., Sharma, K. L., Srivastava, N., Misra, S. \& Mittal, B. Significant role of estrogen and progesterone receptor sequence variants in gallbladder cancer predisposition: a multi-analytical strategy. PLoS One. 7, e40162 (2012).

40. Akin, M. L. et al. Tamoxifen and gallstone formation in postmenopausal breast cancer patients: retrospective cohort study. World J. Surg. 27, 395-399 (2003).

41. Mohamed, A., Kadambari, D. \& Bhuvaneswari, V. Tamoxifen use and gallstone formation in postmenopausal breast cancer patients in south Indian population. Indian. J. Cancer. 46, 151-154 (2009).

42. Fribbens, C. et al. Plasma ESR1 mutations and the treatment of estrogen receptor-positive advanced breast cancer. J. Clin. Oncol. 34, 2961-2968 (2016).

43. Nakazawa, K. et al. Amplification and overexpression of c-erbB-2, epidermal growth factor receptor, and c-met in biliary tract cancers. J. Pathol. 206, 356-365 (2005).

44. Balañá, M. E., Lupu, R., Labriola, L., Charreau, E. H. \& Elizalde, P. V. Interactions between progestins and heregulin (HRG) signaling pathways: HRG acts as mediator of progestins proliferative effects in mouse mammary adenocarcinomas. Oncogene. 18, 6370-6379 (1999).

45. Peck, J. et al. HER2/neu may not be an interesting target in biliary cancers: results of an early phase II study with lapatinib. Oncology. 82, 175-179 (2012).

46. Ramanathan, R. K. et al. A phase II study of lapatinib in patients with advanced biliary tree and hepatocellular cancer. Cancer Chemother. Pharmacol. 64, 777-783 (2009).

47. Hainsworth, J. D. et al. Targeted Therapy for Advanced Solid Tumors on the Basis of Molecular Profiles: Results From MyPathway, an Open- Label, Phase IIa Multiple Basket Study. J. Clin. Oncol. 36, 536-542 (2018).

48. Li, B. T. et al. A multi-histology basket trial of ado-trastuzumab emtansine in patients with HER2 amplified cancers. J. Clin. Oncol. 36, 2502 (2018).

49. Hyman, D. M. et al. HER kinase inhibition in patients with HER2- and HER3-mutant cancers. Nature. 554, 189-194 (2018).

50. Hezel, A. F., Deshpande, V. \& Zhu, A. X. Genetics of biliary tract cancers and emerging targeted therapies. J. Clin. Oncol. 28, 3531-3540 (2010).

51. Yadav, S. et al. Targeted gene sequencing of gallbladder carcinoma identifies high-impact somatic and rare germline mutations. Cancer Genomics Proteomics. 14, 495-506 (2017).

52. Javle, M. et al. Molecular characterization of gallbladder cancer using somatic mutation profiling. Hum. Pathol. 45, 701-708 (2014).

53. Wardell, C. P. et al. Genomic characterization of biliary tract cancers identifies driver genes and predisposing mutations. J. Hepatol. 68, 959-969 (2018).

54. Cohen, D. A. et al. Interobserver agreement among pathologists for semiquantitative hormone receptor scoring in breast carcinoma. Am. J. Clin. Pathol. 138, 796-802 (2012).

55. Duchnowska, R. et al. Predicting early brain metastases based on clinicopathological factors and gene expression analysis in advanced HER2-positive breast cancer patients. J. Neurooncol. 122, 205-216 (2015).

\section{Acknowledgements}

The authors wish to thank Mr. Artur Żok for graphics preparation and Prof. Ben Stanley for linguistic check. This work was supported by the Military Institute of Medicine in Warsaw, Poland structural and statutory funding No. WIM/404.

\section{Author contributions}

Study concepts - B.H., R.P. and R.D. Study design - B.H., R.P. and R.D.; Data acquisition - B.H., R.P., M.B., B.S., B.R., K.W., J.Ż., N.C., M.I. and R.D.; Quality control of data and algorithms -B.H., R.P., M.B., B.S., B.R., K.W., J.Ż., N.C., M.I. and R.D.; Data analysis and interpretation - B.H., R.P., M.B., B.S., B.R., K.W., J.Ż., N.C., M.I. and R.D.; Manuscript preparation - B.H., M.B., J.Ż. and R.D.; Manuscript review - B.H., R.P., M.B., B.S., B.R., K.W., J.Ż., N.C., M.I. and R.D.

\section{Competing interests}

The authors declare no competing interests.

\section{Additional information}

Correspondence and requests for materials should be addressed to R.D.

Reprints and permissions information is available at www.nature.com/reprints.

Publisher's note Springer Nature remains neutral with regard to jurisdictional claims in published maps and institutional affiliations.

Open Access This article is licensed under a Creative Commons Attribution 4.0 International License, which permits use, sharing, adaptation, distribution and reproduction in any medium or format, as long as you give appropriate credit to the original author(s) and the source, provide a link to the Creative Commons license, and indicate if changes were made. The images or other third party material in this article are included in the article's Creative Commons license, unless indicated otherwise in a credit line to the material. If material is not included in the article's Creative Commons license and your intended use is not permitted by statutory regulation or exceeds the permitted use, you will need to obtain permission directly from the copyright holder. To view a copy of this license, visit http://creativecommons.org/licenses/by/4.0/.

(C) The Author(s) 2020 